\title{
Clinical Metabolomics and Glaucoma
}

\author{
João Barbosa-Breda Uwe Himmelreich Bart Ghesquière \\ Amândio Rocha-Sousa Ingeborg Stalmans \\ Laboratory of Ophthalmology, Department of Neurosciences, KU Leuven, Leuven, Belgium
}

\section{Keywords}

Glaucoma · Clinical · Pathophysiology · Biomarker ·

Metabolomics

\begin{abstract}
Glaucoma is one of the leading causes of irreversible blindness worldwide. However, there are no biomarkers that accurately help clinicians perform an early diagnosis or detect patients with a high risk of progression. Metabolomics is the study of all metabolites in an organism, and it has the potential to provide a biomarker. This review summarizes the findings of metabolomics in glaucoma patients and explains why this field is promising for new research. We identified published studies that focused on metabolomics and ophthalmology. After providing an overview of metabolomics in ophthalmology, we focused on human glaucoma studies. Five studies have been conducted in glaucoma patients and all compared patients to healthy controls. Using mass spectrometry, significant differences were found in blood plasma in the metabolic pathways that involve palmitoylcarnitine, sphingolipids, vitamin D-related compounds, and steroid precursors. For nuclear magnetic resonance spectroscopy, a high glutamine-glutamate/creatine ratio was found in the vitreous and lateral geniculate body; no differences were detected in the optic radiations, and a lower $\mathrm{N}$-acetylaspartate/ choline ratio was observed in the geniculocalcarine and stri-
\end{abstract}

\section{KARGER}

(C) 2017 S. Karger AG, Basel

E-Mail karger@karger.com

www.karger.com/ore ate areas. Metabolomics can move glaucoma care towards a personalized approach and provide new knowledge concerning the pathophysiology of glaucoma, which can lead to new therapeutic options.

(c) 2017 S. Karger AG, Basel

\section{Metabolomics}

Metabolomics is the scientific study of the metabolic fingerprints that all cellular processes leave behind in a biological sample [1]. It provides a global perspective of all biochemical processes occurring in an organism at a certain time. Conversely, metabonomics, as it was first named by Jeremy Nicholson, refers to "the quantitative measurement of the dynamic multiparametric metabolic response of living systems to pathophysiological stimuli or genetic modification" $[2,3]$. Metabolomics is the most recent of the "omics" fields, and it differs from other omics technologies because it considers the dynamic status of the human body. However, the concept behind the field can be traced back to the beginning of the last century, when physicians already understood the value of metabolites in the study of diseases [4]. The amount of knowledge gathered is rapidly growing, and in recent years the research subject has begun to change from in vitro and animal models to in vivo and human samples,

João Barbosa-Breda

Laboratory of Ophthalmology, Herestraat 49

BE-3000 Leuven (Belgium)

E-Mail joao_breda@ hotmail.com 
which brings this technology closer to the patients' "bedsides" and enhances its clinical relevance. This research field can provide biomarkers and lead to a better understanding of the pathophysiologies underlying several diseases. The identified metabolites and metabolic pathways are closer to the phenotype than many other omics technologies; therefore, they are more easily translatable to clinical practice [5]. The metabolome is the sum of all metabolites in an organism, the result of internal processes (gene expression, protein activity, and cell metabolism) and the interaction between an organism and "external" factors (e.g.) diet, health status, lifestyle, gut microbiome, drugs) [6, 7]. Metabolomics can be studied in organisms/ whole organs, tissues, and fluids, in vitro and in vivo, either directly at eye level or systemically. The 2 main technologies currently used for these studies are mass spectrometry, which is more sensitive and can cover a wider range of metabolites but destroys the analyzed sample, and nuclear magnetic resonance (NMR) spectroscopy, which primarily detects soluble metabolites, does not destroy the sample, and can analyze in vivo samples noninvasively and repeatedly over time $[8,9]$. Both technologies can simultaneously quantify a large number (hundreds to thousands) of metabolites, in a nontargeted approach, which has been defined as metabolic phenotyping or "metabotyping" [7].

\section{Metabolomics in Ophthalmology}

In ophthalmology, metabolomics has been used to study various eye diseases including glaucoma [10-16], age-related macular degeneration [17-19], diabetic retinopathy [20-22], keratoconus [23], refractive error [24, $25]$, retinal detachment [26], uveitis [27, 28], dry eye [29, 30], and other ocular surface diseases [31]. Analyses have been performed on tear fluid [23, 29-32], aqueous humor $[24,25,33,34]$, vitreous humor $[20,26,27,35,36]$, cornea [37-39], conjunctiva [40], and lens [41, 42] samples.

This review aims to explain the importance of metabolomics in glaucoma and to summarize the findings of human studies.

\section{Metabolomics in Glaucoma}

Glaucoma is one of the leading causes of irreversible blindness worldwide [43], and the number of patients is expected to increase due to the aging population [44]. However, fast and reliable diagnostic methods are lack- ing. Indeed, clinicians rely substantially on regular structural and functional examinations until irreversible damage is detected. Moreover, substantial heterogeneity exists among patients. The incidence differs considerably between races, and the clinical manifestation and progression profiles are variable [11]. Genetic mutations and common genetic variants have been linked to several types of glaucoma, but these factors can only explain a small portion of all cases [45].

After establishing the diagnosis, clinicians face considerable uncertainty during the follow-up. The individual rate of progression varies considerably between patients, and it is impossible to know which patients will progress faster; therefore, intensive follow-up is advised (according to glaucoma management guidelines) until the rate is known [46-50]. To avoid an unacceptable burden on future health resources, it is important to better stratify patients according to their risk profiles. This process would allow more resources to be allocated to patients who are at higher risk of blindness (and avoid wasting resources on patients who do not need them) [51, 52]. Metabolomics has the potential to identify biomarkers that can be used for glaucoma diagnosis and prognosis. These results would allow for earlier diagnoses, when more visual function can be spared and less money spent on surgeries and frequent consultations, and, concurrently, help to better allocate the finite resources we have for high-risk patients.

The correlation between metabolomics and disease progression has not been studied, thus far, for any ophthalmological disease. However, a correlation with disease stage has been shown for diabetic retinopathy [21], as well as age-related macular degeneration $[18,19]$. Similar studies have been conducted in cancer research, one of the largest areas of metabolomics research; preserved blood and urine samples have been used to metabotype progressive and/or relapsing patients. Some of these studies have focused on blood samples collected longitudinally to obtain data from different disease statuses for each patient [53]. However, glaucoma is a progressive chronic disease that does not have acute stages or recurrence/remission, and perhaps the best approach to understand what drives its progression is to collect either samples from patients with different rates of progression (case-control) or samples from a cohort and later analyze them according to progression outcomes (cohort) instead of longitudinal series of samples. A recent example of this one-time sample collection approach is a study of chronic lymphocytic leukemia patients (case-control) in which the authors sought to identify prognostic markers
2
Ophthalmic Res 2018;59:1-6 DOI: $10.1159 / 000479158$
Barbosa-Breda et al. 
Table 1. Metabolomics in glaucoma patients

\begin{tabular}{|c|c|}
\hline Sample type & Altered metabolites/metabolic pathways \\
\hline $\begin{array}{l}\text { Mass spectrometry } \\
\text { Blood plasma }\end{array}$ & $\begin{array}{l}\text { Metabolic pathways involve } \\
\text { palmitoylcarnitine, sphingolipids, vitamin } \\
\text { D-related compounds, and steroid } \\
\text { precursors }[11]\end{array}$ \\
\hline $\begin{array}{l}\text { NMR spectroscopy } \\
\text { Vitreous } \\
\text { LGB } \\
\text { Optic radiation } \\
\text { Striate area/ } \\
\quad \text { occipital cortex }\end{array}$ & $\begin{array}{l}\text { Higher Glx/Cr ratio [10] } \\
\text { Higher Glx/Cr ratio [10] } \\
\text { No differences [16] } \\
\text { Lower NAA/Cr and Cho/Cr ratios [14] } \\
\text { No differences [13] }\end{array}$ \\
\hline
\end{tabular}

All studies compared glaucoma patients to healthy controls. NMR, nuclear magnetic resonance; LGB, lateral geniculate body; Glx, glutamine and glutamate; $\mathrm{Cr}$, creatine/phosphocreatine; NAA, N-acetylaspartate; Cho, choline/phosphocholine/glycerophosphocholine.

of clinical aggressiveness at the time of diagnosis, which would direct treatment needs because current disease staging systems (Rai and Binet) are unable to discriminate between the stable and progressive forms of the disease in the early stages [54]. The Framingham Heart Study is an example of a metabolomics cohort study, in which baseline samples were used to predict clinical outcomes (diabetes incidence over a 12-year period [55], as well as the risk of metabolic syndrome after 5-7 years of follow-up [56]).

Apart from enabling the detection of different progression statuses, further knowledge regarding the pathophysiology of glaucoma can potentially create new drug development research lines, thereby expanding the potential therapeutic targets that we currently have available. Today, the mainstay of treatment relies on lowering intraocular pressure, either with medical or with surgical treatment. Although intraocular pressure is the primary risk factor, some patients present with glaucomatous neuropathy and progress towards blindness with lowerthan-normal intraocular pressure values. Thus, we can conclude that other mechanisms exist for retinal ganglion cell death. A reduction or dysregulation of blood supply to the optic nerve is one potential mechanism in which local and/or systemic conditions, such as systemic hypotension [57-59], would favor an ischemic insult of the optic nerve [60]. Other potential damage pathways are increased apoptosis (increased neurotoxicity, neurotrophin depletion) and oxidative stress, among others.

Clinical Metabolomics and Glaucoma
Several oxidative stress markers have already been shown to exist in the blood and aqueous humor of glaucoma patients (malonyldialdehyde was found to be the best serum biomarker) compared to controls [61-64]. Hence, we can conclude that glaucoma is a multifactorial disease.

In addition to local factors, systemic conditions have been shown to influence glaucoma pathogenesis. Therefore, metabolomics of ocular and systemic samples will potentially contribute to a better understanding and early diagnosis of glaucoma (Table 1). Indeed, a blood-plasma comparison between primary open-angle glaucoma patients and healthy controls using mass spectrometry found significant differences in specific metabolic processes involving palmitoylcarnitine, sphingolipids, vitamin D-related compounds, and steroid precursors. These observations might be linked to mitochondrial dysfunction and energy metabolism changes [11]. This study was the first attempt to perform a metabolome-wide analysis of glaucoma patients. Future studies can focus on certain glaucoma endotypes and investigate other sample types, such as aqueous humor or vitreous. In addition, excluding prevalent systemic diseases that can considerably alter metabolism, such as diabetes, might allow for a more accurate identification of glaucoma biomarkers.

In terms of NMR spectroscopy, several in vivo studies have been performed to assess the brain metabolite changes in glaucoma patients. Using localized, singlevoxel in vivo NMR spectroscopy, no significant changes were found in the concentrations of typical metabolites $\mathrm{N}$-acetylaspartate (NAA), creatine/phosphocreatine (Cr), and choline/phosphocholine/glycerophosphocholine (Cho) in the striate area compared to healthy controls [13]. However, the authors explained that this result might have been due to the slowly progressive nature of the disease because a substantial proportion of the decrease in the neuronal marker NAA occurs in the acute phase of cell degeneration. Another possible explanation is that the affected region might have been too small to allow for proper measurement, requiring more advanced NMR spectroscopic approaches. Later, a study performed with multiple-voxel NMR spectroscopy found lower $\mathrm{NAA} / \mathrm{Cr}$ and $\mathrm{Cho} / \mathrm{Cr}$ ratios in the geniculocalcarine and striate areas of glaucoma patients when comparing them to age- and gender-matched healthy controls [14]. A similar study was conducted in a rat model of ocular hypertension, and a lower $\mathrm{Cho} / \mathrm{Cr}$ ratio was also found in the visual cortex 6 weeks after the start of ocular hypertension. However, no significant differences were found in other metabolites, including NAA, glutamine, and glutamate [15]. These changes could point towards a patho-

Ophthalmic Res 2018;59:1-6 DOI: $10.1159 / 000479158$ 
physiological mechanism of glaucoma involving a dysfunction of the cholinergic system. Hence, the Cho/Cr ratio could potentially serve as a noninvasive biomarker.

The vitreous has also been studied in human patients. In view of the apoptosis theory, in which the neurotoxicity of glutamate plays a pivotal role, a study was conducted with in vivo single-voxel NMR spectroscopy of the vitreous and lateral geniculate body of glaucoma patients. The authors found a higher glutamine-glutamate/Cr ratio in the vitreous and in the lateral geniculate body compared to healthy controls [10]. All of the study subjects were Caucasian, and hypertension, diabetes, and degenerative central nervous system diseases were excluded. No significant changes were found in the NAA/Cr and $\mathrm{Cho/Cr}$ ratios in the lateral geniculate body. These findings support the apoptosis theory, in which glutamate is one of the main contributing factors to neurotoxicity. Similar changes have been found when using high-pressure liquid chromatography to analyze vitreous samples of glaucoma patients [65]. Another study with the same technique showed no changes in glutamate in vitreous samples from glaucoma patients [66]. However, this result might have been due to the small sample size (8 glaucoma patients) and the heterogeneous sample (AxenfeldRieger and uveitis were also included) in the latter.

Recently, the metabolic pattern of optic radiations was compared between glaucoma patients and healthy controls, using a single-voxel NMR spectroscopy approach. The authors investigated the metabolite changes according to disease severity. No significant differences were found between groups or between disease severity levels. This result might have been due to a different site chosen for the measurement, a different (single- vs. multiplevoxel) technique applied, and/or significant age differences between the groups [16].

\section{Pitfalls of Metabolomic Studies}

In metabolomic studies, it is important to prevent and correct for sources of bias, such as age and gender, diet and lifestyle, the time of day of sample collection, and temperature and time to storage. In addition, systemic diseases and intake of drugs and supplements can potentially alter the metabolome and should be accounted for. Despite this, some studies have already been conducted with previously preserved samples (5-9 years) collected and handled under suboptimal conditions. For instance, one study investigated blood and urine metabolic differences in patients with multiple myeloma. Samples were collected at different times of the day, with no fasting, and they were delivered by post, thus spending 1-3 days at ambient temperature. Even under such conditions, significant differences were found between newly diagnosed myeloma requiring therapy, remission after treatment, and relapse patient groups. Bias sources were clearly present, and the findings should be viewed under that consideration, but the findings still support researchers who argue that standardization of procedures is more important than the best collection and handling conditions [67].

Data analysis and statistics are also important. Although the number of metabolomics libraries and the amount of knowledge increase every day, there are still several peaks in spectra that cannot be linked to known metabolites or metabolic pathways. In addition, there are many detectable metabolites; therefore, a proper statistical analysis must be performed to account for multiple comparisons and a high level of false positives (e.g., Benjamini-Hochberg false discovery rate-controlling procedure) $[2,5,6,68-72]$. Due to the large number of detectable metabolites, in particular in the spectra of ex vivo tissue and biofluid samples, quantification of individual metabolites is often not feasible. Therefore, automated analyses that do not require the assignment of spectral peaks to particular compounds are used [73]. Although they are of high diagnostic value, these methods make it harder to link the acquired data to the underlying metabolic pathways [74].

\section{Conclusion}

Glaucoma remains a poorly understood disease, with a small range of therapeutic options. Metabolomics has the potential to provide biomarkers that can be used as an add-on to the currently available diagnostic, classification, and progression detection tools. Furthermore, this technology can provide further knowledge regarding the pathophysiology behind this disease, which could lead to new drug development research lines. The future of medicine is moving towards a personalized approach, and metabolomics will be an important tool in patient profiling and precision medicine.

\section{Disclosure Statement}

The authors declare no conflict of interests.
4 Ophthalmic Res 2018;59:1-6
Barbosa-Breda et al. 


\section{References}

1 Oliver SG, Winson MK, Kell DB, Baganz F: Systematic functional analysis of the yeast genome. Trends Biotechnol 1998;16:373-378.

2 Nicholson JK, Lindon JC, Holmes E: "Metabonomics": understanding the metabolic responses of living systems to pathophysiological stimuli via multivariate statistical analysis of biological NMR spectroscopic data. Xenobiotica 1999;29:1181-1189.

3 Faber JH, Malmodin D, Toft H, Maher AD, Crockford D, Holmes E, et al: Metabonomics in diabetes research. J Diabetes Sci Technol 2007;1:549-557.

4 Warburg O, Wind F, Negelein E: The metabolism of tumors in the body. J Gen Physiol 1927;8:519-530.

5 Kell DB, Brown M, Davey HM, Dunn WB, Spasic I, Oliver SG: Metabolic footprinting and systems biology: the medium is the message. Nat Rev Microbiol 2005;3:557-565.

6 Nicholson JK, Wilson ID: Opinion: understanding "global" systems biology: metabonomics and the continuum of metabolism. Nat Rev Drug Discov 2003;2:668-676.

7 Beger RD, Dunn W, Schmidt MA, Gross SS, Kirwan JA, Cascante M, et al: Metabolomics enables precision medicine: "A White Paper, Community Perspective". Metabolomics 2016;12:149

8 Li S, Todor A, Luo R: Blood transcriptomics and metabolomics for personalized medicine. Comput Struct Biotechnol J 2016;14:1-7.

9 Himmelreich U MC, Sorrell TC: NMR spectroscopic determination of microbiological profiles in infectious diseases. Trends Appl Spectrosc 2004;269-283.

10 Doganay S, Cankaya C, Alkan A: Evaluation of corpus geniculatum laterale and vitreous fluid by magnetic resonance spectroscopy in patients with glaucoma: a preliminary study. Eye (Lond) 2012;26:1044-1051.

11 Burgess LG, Uppal K, Walker DI, Roberson RM, Tran V, Parks MB, et al: Metabolomewide association study of primary open angle glaucoma. Invest Ophthalmol Vis Sci 2015; 56:5020-5028.

12 Mayordomo-Febrer A, Lopez-Murcia M, Morales-Tatay JM, Monleon-Salvado D, Pinazo-Duran MD: Metabolomics of the aqueous humor in the rat glaucoma model induced by a series of intracamerular sodium hyaluronate injection. Exp Eye Res 2015;131: 84-92.

13 Boucard CC, Hoogduin JM, van der Grond J, Cornelissen FW: Occipital proton magnetic resonance spectroscopy (1H-MRS) reveals normal metabolite concentrations in retinal visual field defects. PLoS One 2007;2:e222.

14 Zhang Y, Chen X, Wen G, Wu G, Zhang X: Proton magnetic resonance spectroscopy ((1) $\mathrm{H}$-MRS) reveals geniculocalcarine and striate area degeneration in primary glaucoma. PLoS One 2013;8:e73197.
15 Chan KC, So KF, Wu EX: Proton magnetic resonance spectroscopy revealed choline reduction in the visual cortex in an experimental model of chronic glaucoma. Exp Eye Res 2009;88:65-70.

16 Sidek S, Ramli N, Rahmat K, Ramli NM, Abdulrahman F, Kuo TL: In vivo proton magnetic resonance spectroscopy (1H-MRS) evaluation of the metabolite concentration of optic radiation in primary open angle glaucoma. Eur Radiol 2016;26:4404-4412.

17 Osborn MP, Park Y, Parks MB, Burgess LG, Uppal K, Lee K, et al: Metabolome-wide association study of neovascular age-related macular degeneration. PLoS One 2013; 8:e72737.

18 Lains I, Kelly RS, Lasky-Su J, Murta JN, Miller JB, et al: Plasma mass-spectrometry metabolomics in age-related macular degeneration. Abstract Am Assoc Res Vis Ophthalmol Annu Meet, Baltimore, 2017.

19 Laíns I, Duarte D, Barros AS, Martins AS, Gil J, Miller JB, et al: Human plasma metabolomics in age-related macular degeneration (AMD) using nuclear magnetic resonance spectroscopy. PLoS One 2017;12:e0177749.

20 Barba I, Garcia-Ramirez M, Hernandez C, Alonso MA, Masmiquel L, Garcia-Dorado D, et al: Metabolic fingerprints of proliferative diabetic retinopathy: an $1 \mathrm{H}-\mathrm{NMR}$-based metabonomic approach using vitreous humor. Invest Ophthalmol Vis Sci 2010;51: 4416-4421.

21 Li X, Luo X, Lu X, Duan J, Xu G: Metabolomics study of diabetic retinopathy using gas chromatography-mass spectrometry: a comparison of stages and subtypes diagnosed by Western and Chinese medicine. Mol Biosyst 2011;7:2228-2237.

22 Chen L, Cheng CY, Choi H, Ikram MK, Sabanayagam C, Tan GS, et al: Plasma metabonomic profiling of diabetic retinopathy. Diabetes 2016;65:1099-1108.

23 Karamichos D, Zieske JD, Sejersen H, SarkerNag A, Asara JM, Hjortdal J: Tear metabolite changes in keratoconus. Exp Eye Res 2015; 132:1-8.

24 Barbas-Bernardos C, Armitage EG, Garcia A, Merida S, Navea A, Bosch-Morell F, et al: Looking into aqueous humor through metabolomics spectacles - exploring its metabolic characteristics in relation to myopia. J Pharm Biomed Anal 2016;127:18-25.

25 Ji Y, Rao J, Rong X, Lou S, Zheng Z, Lu Y: Metabolic characterization of human aqueous humor in relation to high myopia. Exp Eye Res 2017;159:147-155.

26 Li M, Li H, Jiang P, Liu X, Xu D, Wang F: Investigating the pathological processes of rhegmatogenous retinal detachment and proliferative vitreoretinopathy with metabolomics analysis. Mol Biosyst 2014;10:1055-1062.
27 Young SP, Nessim M, Falciani F, Trevino V, Banerjee SP, Scott RA, et al: Metabolomic analysis of human vitreous humor differentiates ocular inflammatory disease. Mol Vis 2009;15:1210-1217.

28 Guo J, Yan T, Bi H, Xie X, Wang X, Guo D, et al: Plasma metabonomics study of the patients with acute anterior uveitis based on ultra-performance liquid chromatographymass spectrometry. Graefes Arch Clin Exp Ophthalmol 2014;252:925-934.

29 Galbis-Estrada C, Martinez-Castillo S, Morales JM, Vivar-Llopis B, Monleon D, DiazLlopis M, et al: Differential effects of dry eye disorders on metabolomic profile by $1 \mathrm{H} \mathrm{nu}$ clear magnetic resonance spectroscopy. Biomed Res Int 2014;2014:542549.

30 Galbis-Estrada C, Pinazo-Duran MD, Martinez-Castillo S, Morales JM, Monleon D, Zanon-Moreno V: A metabolomic approach to dry eye disorders: the role of oral supplements with antioxidants and omega 3 fatty acids. Mol Vis 2015;21:555-567.

31 Zhou L, Beuerman RW: Tear analysis in ocular surface diseases. Prog Retin Eye Res 2012; 31:527-550.

32 Munoz-Hernandez AM, Galbis-Estrada C, Santos-Bueso E, Cuina-Sardina R, Diaz-Valle D, Gegundez-Fernandez JA, et al: Human tear metabolome. Arch Soc Esp Oftalmol 2016;91: 157-159.

33 Brown JC, Sadler PJ, Spalton DJ, Juul SM, Macleod AF, Sonksen PH: Analysis of human aqueous humour by high resolution $1 \mathrm{H}$ NMR spectroscopy. Exp Eye Res 1986;42:357-362.

34 Tkadlecová M, Havlíček J, Volka K, Souček P, Karel I: Study of aqueous humour by $1 \mathrm{H}$ NMR spectroscopy. J Mol Struct 1999;480481:601-605.

35 Berkowitz BA, Bansal N, Wilson CA: Noninvasive measurement of steady-state vitreous lactate concentration. NMR Biomed 1994;7:263-268.

36 Rucker JC, Biousse V, Mao H, Sandbach J, Constantinidis I, Newman NJ: Detection of lactate in the human vitreous body using proton magnetic resonance spectroscopy. Arch Ophthalmol 2003;121:909-911.

37 Midelfart A, Dybdahl A, Gribbestad IS: Metabolic analysis of the rabbit cornea by proton nuclear magnetic resonance spectroscopy. Ophthalmic Res 1996;28:319-329.

38 Priyadarsini S, McKay TB, Sarker-Nag A, Allegood J, Chalfant C, Ma JX, et al: Complete metabolome and lipidome analysis reveals novel biomarkers in the human diabetic corneal stroma. Exp Eye Res 2016;153:90-100.

39 Saether O, Krane J, Risa O, Cejkova J, Midelfart A: High-resolution MAS 1H NMR spectroscopic analysis of rabbit cornea after treatment with dexamethasone and exposure to UV-B radiation. Curr Eye Res 2005;30:10411049.

Clinical Metabolomics and Glaucoma

Ophthalmic Res 2018;59:1-6 
40 Chen L, Li J, Guo T, Ghosh S, Koh SK, Tian $\mathrm{D}$, et al: Global metabonomic and proteomic analysis of human conjunctival epithelial cells (IOBA-NHC) in response to hyperosmotic stress. J Proteome Res 2015;14:3982-3995.

41 Midelfart A, Dybdahl A, Gribbestad S: Detection of different metabolites in the rabbit lens by high resolution $1 \mathrm{H}$ NMR spectroscopy. Curr Eye Res 1996;15:1175-1181.

42 Tsentalovich YP, Verkhovod TD, Yanshole VV, Kiryutin AS, Yanshole LV, Fursova A, et al: Metabolomic composition of normal aged and cataractous human lenses. Exp Eye Res 2015;134:15-23.

43 Kingman S: Glaucoma is second leading cause of blindness globally. Bull World Health Organ 2004;82:887-888.

44 Quigley HA, Broman AT: The number of people with glaucoma worldwide in 2010 and 2020. Br J Ophthalmol 2006;90:262-267.

45 Moroi SE, Raoof DA, Reed DM, Zollner S, Qin Z, Richards JE: Progress toward personalized medicine for glaucoma. Expert Rev Ophthalmol 2009;4:145-161.

46 Glaucoma: Diagnosis and Management of Chronic Open Angle Glaucoma and Ocular Hypertension. London, National Institute for Health and Clinical Excellence: Guidance, 2009.

47 Terminology and Guidelines for Glaucoma, ed 4. Zug, European Glaucoma Society, 2014.

48 International Council of Ophthalmology: ICO Guidelines for Glaucoma Eye Care. San Francisco, ICO, 2016.

49 Burr JM, Botello-Pinzon P, Takwoingi Y, Hernandez R, Vazquez-Montes M, Elders A, et al: Surveillance for ocular hypertension: an evidence synthesis and economic evaluation. Health Technol Assess 2012;16:1-271, iii-iv.

50 American Academy of Ophthalmology: Preferred Practice Patterns: Open-Angle Glaucoma. San Francisco, AAO, 2015.

51 Tuulonen A: Challenges of glaucoma care high volume, high quality, low cost. Acta Ophthalmol 2013;91:3-5.

52 Tuulonen A, Kataja M, Syvanen U, Miettunen S, Uusitalo H: Right services to right patients at right time in right setting in Tays Eye Centre. Acta Ophthalmol 2016;94:730-735.
53 Asiago VM, Alvarado LZ, Shanaiah N, Gowda GA, Owusu-Sarfo K, Ballas RA, et al: Early detection of recurrent breast cancer using metabolite profiling. Cancer Res 2010;70:83098318.

54 Piszcz J, Armitage EG, Ferrarini A, Ruperez FJ, Kulczynska A, Bolkun L, et al: To treat or not to treat: metabolomics reveals biomarkers for treatment indication in chronic lymphocytic leukaemia patients. Oncotarget 2016;7: 22324-22338.

55 Wang TJ, Larson MG, Vasan RS, Cheng S, Rhee EP, McCabe E, et al: Metabolite profiles and the risk of developing diabetes. Nat Med 2011;17:448-453.

56 Yin X, Subramanian S, Willinger CM, Chen G, Juhasz P, Courchesne P, et al: Metabolite signatures of metabolic risk factors and their longitudinal changes. J Clin Endocrinol Metab 2016;101:1779-1789.

57 Flammer J, Konieczka K, Flammer AJ: The primary vascular dysregulation syndrome: implications for eye diseases. EPMA J 2013;4: 14.

58 Konieczka K, Ritch R, Traverso CE, Kim DM, Kook MS, Gallino A, et al: Flammer syndrome. EPMA J 2014;5:11.

59 Furlanetto RL, De Moraes CG, Teng CC, Liebmann JM, Greenfield DS, Gardiner SK, et al: Risk factors for optic disc hemorrhage in the low-pressure glaucoma treatment study. Am J Ophthalmol 2014;157:945-952.

60 Flammer J, Orgul S, Costa VP, Orzalesi N, Krieglstein GK, Serra LM, et al: The impact of ocular blood flow in glaucoma. Prog Retin Eye Res 2002;21:359-393.

61 Baltmr A, Duggan J, Nizari S, Salt TE, Cordeiro MF: Neuroprotection in glaucoma - is there a future role? Exp Eye Res 2010;91:554566.

62 Song W, Huang P, Zhang C: Neuroprotective therapies for glaucoma. Drug Des Devel Ther 2015;9:1469-1479.

63 Weinreb RN: Glaucoma neuroprotection: what is it? Why is it needed? Can J Ophthalmol 2007;42:396-398.

64 Benoist d'Azy C, Pereira B, Chiambaretta F, Dutheil F: Oxidative and anti-oxidative stress markers in chronic glaucoma: a systematic review and meta-analysis. PLoS One 2016; 11:e0166915.
65 Dreyer EB, Zurakowski D, Schumer RA, Podos SM, Lipton SA: Elevated glutamate levels in the vitreous body of humans and monkeys with glaucoma. Arch Ophthalmol 1996;114: 299-305.

66 Honkanen RA, Baruah S, Zimmerman MB, Khanna CL, Weaver YK, Narkiewicz J, et al: Vitreous amino acid concentrations in patients with glaucoma undergoing vitrectomy. Arch Ophthalmol 2003;121:183-188.

67 Lodi A, Tiziani S, Khanim FL, Gunther UL, Viant MR, Morgan GJ, et al: Proton NMRbased metabolite analyses of archived serial paired serum and urine samples from myeloma patients at different stages of disease activity identifies acetylcarnitine as a novel marker of active disease. PLoS One 2013;8:e56422.

68 Tan SZ, Begley P, Mullard G, Hollywood KA, Bishop PN: Introduction to metabolomics and its applications in ophthalmology. Eye (Lond) 2016;30:773-783.

69 Midelfart A: Metabonomics - a new approach in ophthalmology. Acta Ophthalmol 2009;87: 697-703.

70 Lenz EM, Bright J, Wilson ID, Hughes A, Morrisson J, Lindberg H, et al: Metabonomics, dietary influences and cultural differences: a $1 \mathrm{H}$ NMR-based study of urine samples obtained from healthy British and Swedish subjects. J Pharm Biomed Anal 2004;36:841849.

71 Johnson JM, Yu T, Strobel FH, Jones DP: A practical approach to detect unique metabolic patterns for personalized medicine. Analyst 2010;135:2864-2870.

72 Chen R, Snyder M: Promise of personalized omics to precision medicine. Wiley Interdiscip Rev Syst Biol Med 2013;5:73-82.

73 Himmelreich U, Sorrell TC, Daniel HM: Nuclear magnetic resonance spectroscopy-based identification of yeast. Methods Mol Biol 2017;1508:289-304.

74 Croitor-Sava A, Beck V, Sandaite I, Van Huffel S, Dresselaers T, Claus F, et al: Highresolution (1)H NMR spectroscopy discriminates amniotic fluid of fetuses with congenital diaphragmatic hernia from healthy controls. J Proteome Res 2015;14:4502-4510. 